\title{
JUSTIÇA DE TRANSIÇÃO E VIOLÊNCIA POLICIAL: REFLEXÕES CRÍTICAS SOBRE A SEGURANÇA PÚBLICA NO BRASIL
}

\author{
Emerson Francisco de Assis*
}

\section{RESUMO}

Este artigo pretende discutir a hipótese de que a violência policial no Brasil, se deve, em grande medida, a falhas na dimensão de reformas institucionais na Segurança Pública no processo transicional brasileiro. Assim, houve a perpetuação de práticas autoritárias da ditadura militar que, possibilitaram no período após a Constituição Federal de 1988, a consolidação de uma polícia que adota uma perspectiva de segurança nacional de guerra contra o crime, incompatível com a democracia, que demanda uma postura mais aberta e cidadã. Para tanto, o artigo analisa indicadores sociais de criminalidade e referencial teórico interdisciplinar em Direitos Humanos e Ciência Política.

Palavras-chaves: Justiça de Transição. Violência Policial. Segurança Pública. Direitos Humanos.

\section{TRANSITIONAL JUSTICE AND POLICE VIOLENCE: CRITICAL REFLECTIONS ON PUBLIC SECURITY IN BRAZIL}

\begin{abstract}
This article aims to discuss the hypothesis that police violence in Brazil is largely due to failures in the dimension of institutional reforms in public security in the Brazilian transitional process. Thus, there was the perpetuation of authoritarian practices of the military dictatorship in the period after the Federal Constitution of 1988, that fact allowed the consolidation of a police force who adopts a national security perspective of war against crime, incompatible with democracy, that demands a wide and democratic posture. For this, the article analyzes social indicators of crime and interdisciplinary theoretical reference in Human Rights and Political Science.
\end{abstract}

Key-words: Transitional Justice. Police Violence. Public Security. Human Rights.

\section{Introdução}

O objetivo deste artigo é discutir a hipótese de que, a violência policial no Brasil, se deve, em larga medida, as falhas ocorridas em reformas institucionais no contexto do processo de Justiça de Transição no país.

\footnotetext{
* Mestre em Ciência Política e Doutorando em Direito pela Universidade Federal de Pernambuco (UFPE), professor dos cursos de Direito e Relações Internacionais do Centro Universitário Tabosa de Almeida (ASCESUNITA) em Caruaru-PE.
} 
Neste sentido, o trabalho defende a perspectiva de que a Constituição Federal de 1988 adotou um modelo equivocado de Segurança Pública, que permitiu a continuidade da lógica do militarismo e, parcialmente, da doutrina de Segurança Nacional para realizar uma verdadeira guerra contra a criminalidade, que se mostra totalmente ineficaz, pois não permite a redução do número de homicídios no país e, por outro lado, é responsável por um grande número de agentes do Estado e civis mortos em operações policiais.

Para tanto, o trabalho foi dividido em três partes: na primeira, será discutido o conceito de Justiça de Transição, seus elementos e eixos basilares e breves apontamentos históricos. Na segunda parte, serão apresentados quatro indicadores sociais sobre violência no Brasil: taxa de homicídios dolosos, número de homicídios dolosos, números de policiais mortos em serviços e número de pessoas mortas em operações policiais. Na última parte do trabalho, serão analisadas as reformas institucionais promovidas no setor de Segurança no Brasil, no contexto da Justiça de Transição.

Este trabalho mescla metodologias qualitativas e quantitativas. O referencial teórico é interdisciplinar na área de Ciência Política e Direitos Humanos. Os dados em números são relativos ao período de 2012 e 2016 , de modo a se constituir um retrato mais próximo da realidade de hoje, e, foram obtidos a partir de fontes confiáveis como: Instituto de Pesquisa Econômica Aplicada (IPEA) e o Fórum Brasileiro de Segurança Pública, o Mapa da Violência e o "United Nations Office on Crimes and Drugs"1 (UNODC).

\section{Apontamentos sobre a Justiça de Transição: conceito e seus principais elementos, eixos ou dimensões}

O termo Justiça de Transição foi criado pela professora argentina Ruti Teitel (2010), para designar uma concepção distinta de justiça associada a períodos de mudança política radical, em vista da superação de um passado autoritário e opressivo. Nas palavras desta autora:

A justiça transicional pode ser definida como a concepção de justiça associada a períodos de mudança política, caracterizados por respostas no âmbito jurídico, que

\footnotetext{
1 "Escritório das Nações Unidas sobre Crimes e Drogas" (tradução livre).
} 
têm o objetivo de enfrentar os crimes cometidos por regimes opressores do passado. (TEITEL, 2011, p. 135):

Outros autores, a exemplo do professor sul-africano Paul van Zyl (2011), também se dedicaram a traçar um conceito sobre a Justiça de Transição: "Pode-se definir a justiça transicional como o esforço para a construção da paz sustentável após um período de conflito, violência em massa ou violação sistemática dos direitos humanos." (VAN ZYL, 2011, p. 47). Na visão deste autor, a Justiça Transicional teria por objetivo processar os perpetradores de violações aos Direitos Humanos durante o período autoritário pretérito, revelar as verdades sobre os crimes então cometidos, reparar as vítimas, reformar instituições que promoveram abusos e promover a reconciliação na sociedade em geral (VAN ZYL, 2011).

Ainda de acordo com Paul van Zyl (2011), a Justiça de Transição é composta por “elementos-chaves”, classificados em cinco espécies: justiça, busca da verdade, reparação, reformas institucionais e reconciliação. O pesquisador brasileiro Renan Quinalha (2013), por sua vez, prefere usar o termo "eixos" para designar os princípios básicos da Justiça de Transição, os dividindo em cinco também: verdade, memória, justiça, reparação e reformas institucional.

Outro pesquisador brasileiro, Paulo Abrão (2012), que também presidiu a Comissão Nacional de Anistia, entende que a Justiça de Transição é composta por quatro dimensões básicas:

(i) a reparação; (ii) o fornecimento da verdade e a construção da memória; (iii) a regularização da justiça e reestabelecimento da igualdade perante a lei; e (iv) a reforma das instituições perpetradoras de violações contra os direitos humanos. (ABRÃO, 2012, p. 59)

Quer sejam “eixos”, “elementos” ou "dimensões”, os princípios básicos dos processos transicionais guardam muita coisa em comum, como esclarece Renan Quinalha (2013, p. 138):

\footnotetext{
Ainda que não se possa, de antemão, traçar um rol taxativo dos elementos constitutivos deste conceito de justiça transicional, que varia a depender da perspectiva adotada e da realidade analisada, há um sentido mínimo e um traço comum nessa diversidade de experiência. As visões tradicionais identificam um corpo e medidas e mecanismos cuja recorrência sugere tratarem-se de aspectos definidores de uma autêntica justiça de transição, decorrendo, daí a dimensão normativa geralmente presente nesse conceito.
}

Segundo ressalta Quinalha (2013), tanto na perspectiva oficial de órgão nacionais e internacionais, quanto em pesquisas acadêmicas, a Justiça de Transição sempre foi entendida 
como: “[...] uma constelação composta por quatro ou cinco eixos centrais [...]." (QUINALHA, 2013, p. 138).

Diante do exposto é possível perceber que os eixos, elementos ou dimensões da Justiça de Transição são passos necessários para completar um processo de redemocratização. Por isso, mesmo com ligeira variação em aspectos de terminologia, é claro que os elementos abordados por diversos autores acabam sendo basicamente os mesmos. Afinal, eles implicam no fato de que, de um modo geral, um processo transicional que se queira efetivo precisa adotar medidas que levem a superação do passado autoritário e que sejam o alicerce de uma nova democracia. Garantir a memória e a verdade sobre a ditadura superada, punir os agentes repressores, indenizar as vítimas e seus familiares, bem como reformar as instituições estatais para que as arbitrariedades do passado não se repitam no presente, além de elementos fundamentais dos processos transicionais são pilares que sustentam a construção de uma nova democracia.

Em relação ao histórico da Justiça de Transição, a despeito desta ter um conceito recente, a ideia de realização de um processo de redemocratização através do acerto de contas com o passado autoritário vem de longa data. Neste sentido, o filósofo norueguês Jon Elster (2006) recorda que o governo democrático da polis de Atenas teve que lidar com a transição de dois governos autocráticos no século IV AC. Contudo, Ruti Teitel (2011) ressalta que somente após a Primeira Guerra Mundial é que se pode falar em uma ideia moderna de Justiça de Transição. Ao seu turno, o professor norte-americano Louis Bickford (2004) entende que somente a partir da Segunda Guerra Mundial é que se consolida realmente a Justiça de Transição, especialmente após os julgamentos do Tribunal de Nuremberg. Todavia, este último autor frisa que somente nas duas últimas décadas do século XX, a Justiça de Transição ganhou destaque mundial a partir da queda das ditaduras militares da Grécia na Europa, bem como na Argentina e demais países latino-americanos.

No tocante ao desenvolvimento da Justiça de Transição propriamente dita, Paul van Zyl (2011) informa que no começo do século XXI, o campo da Justiça de Transição se desenvolveu em dois sentidos importantes: primeiramente, os elementos da Justiça Transicional passaram por um processo de acolhimento internacional, através de sua aplicação por tribunais internacionais como a Corte Interamericana de Direitos Humanos ou a Corte Europeia de Direitos Humanos. Isto possibilitou o seguinte fato: “[...] atualmente existem padrões claros relativos às obrigações dos Estados a respeito da forma de enfrentar as 
violações dos direitos humanos, bem como proibições, como no caso das anistias gerais quando se trata de crimes internacionais.” (VAN ZYL, 2011, pp. 47-48).

Em segundo plano, a Justiça de Transição permitiu o fortalecimento da democracia no mundo inteiro, especialmente na América Latina, África e Ásia, bem como o surgimento de organizações da sociedade civil em prol da defesa de democracia e dos Direitos Humanos. De forma geral, isto tem permitido não só fundar instituições, mas criar a vontade política necessária para enfrentar o legado de violações aos Direitos Humanos e promover ações precisas para a consolidação plena da democracia (VAN ZYL, 2011).

Após estas breves considerações basilares sobre a Justiça de Transição, no próximo tópico serão discutidos indicadores sociais relativos a violência no Brasil de hoje.

\section{Violência no Brasil contemporâneo: homicídios dolosos, mortes em ações policiais e agentes mortos em serviço}

Este tópico se destina a discutir alguns indicadores sociais sobre criminalidade no Brasil, quer seja: o número total de homicídios dolosos, a taxa de homicídios dolosos por 100.000 habitantes, o número de mortes de civis decorrentes de ações policiais e o número destes profissionais que morreram em confronto no exercício de suas atividades. O período de análise foi delimitado entre 2012 e $2016^{2}$, para se ter um retrato o mais próximo possível da realidade presente do país. Os dados são originários de fontes confiáveis como o Instituto de Pesquisa Econômica Aplicada (IPEA, 2018) e o Fórum Brasileiro de Segurança Pública (2018), o Mapa da Violência (WAISELFISZ, 2016) e o "United Nations Office on Crimes and Drugs" (UNODC, 2013).

Nestes termos, o primeiro indicador social abordado será o número de homicídios dolosos no Brasil, conforme figura abaixo:

\footnotetext{
${ }^{2}$ Dados relativos a 2017 ainda não estavam disponíveis quando da conclusão deste trabalho em fevereiro de 2018.
} 


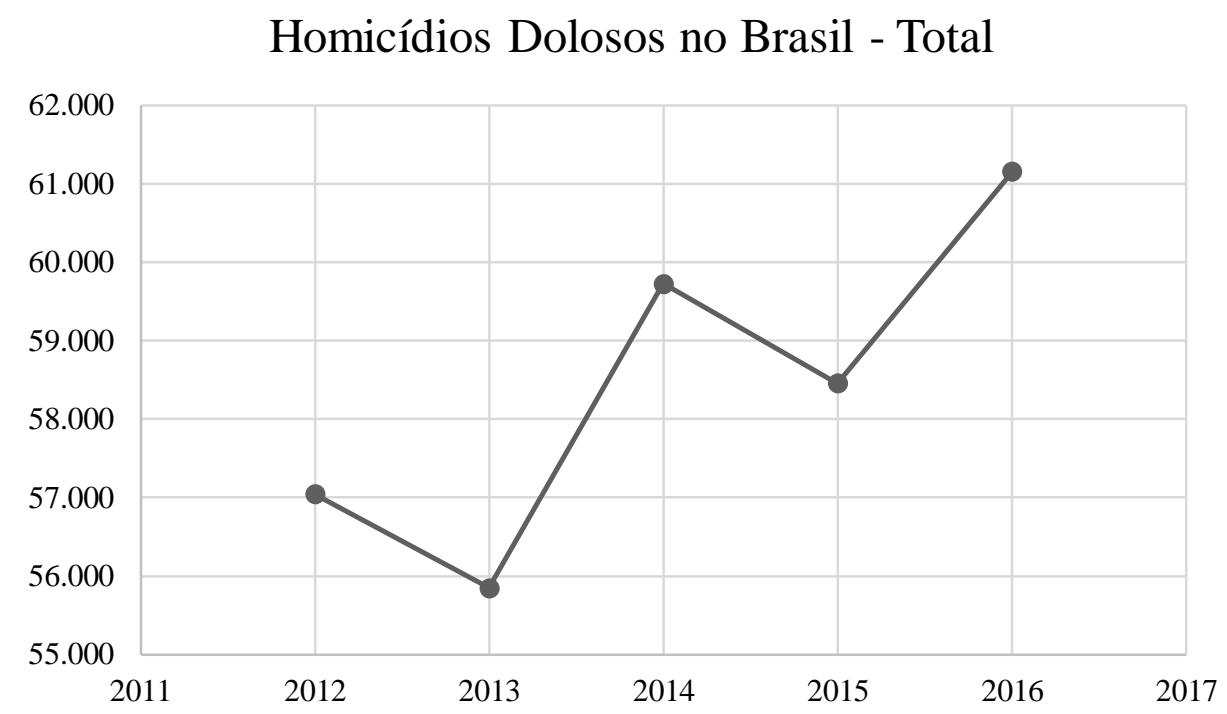

Fig. 01 - Homicídios Dolosos no Brasil - Total (2012-2016), Fontes dos Dados: (IPEA, 2018; FORUM BRASILEIRO DE SEGURANÇA PÚBLICA, 2018).

Como se pode ver na figura acima, o número total de homicídios dolosos no Brasil durante o período em análise, quer seja, de 2012-2016 está em franca expansão. Assim, em 2012 foram verificados 57.045 assassinatos no país, no ano seguinte, 2013, este número baixou um pouco, sendo totalizadas 55.847 mortes através de homicídios. Em 2014, ao turno, o crescimento compensou a retração do período anterior, se alcançando um total de 59.730 ocorrências do delito em debate. Prosseguindo, no ano de 2015, houve novo decréscimo nos números, e 58.459 homicídios dolosos foram registrados no Brasil. Por fim, em 2016 se verificaram 61.158 assassinatos no país, selando a tendência de aumento do período em discussão (IPEA, 2018; FÓRUM BRASILEIRO DE SEGURANÇA PÚBLICA, 2018).

Desta forma, entre o começo e o fim da fase em análise, isto é, de 2012 a 2016, houve um acréscimo geral de 7,21\% nos homicídios dolosos verificados no Brasil. Aparentemente não é um número alto, mas considerando que o Brasil tem em todos os anos analisados mais de 50.000 homicídios dolosos, este é um dado que não deve ser desprezado.

Além disso, este quantitativo de mortos em crimes contra a vida, revela um fato muito preocupante sobre a segurança pública nacional, como salienta o sociólogo argentinobrasileiro Julio Jacobo Waiselfisz (2016), em seu conhecido estudo, denominado "Mapa da Violência":

O Brasil, sem conflitos religiosos ou étnicos, de cor ou de raça, sem disputas territoriais ou de fronteiras, sem guerra civil ou enfrentamentos políticos, consegue a 
façanha de vitimar, por armas de fogo, mais cidadãos do que muitos dos conflitos armados contemporâneos, como a guerra da Chechênia, a do Golfo, as várias intifadas, as guerrilhas colombianas ou a guerra de liberação de Angola e Moçambique, ou, ainda, uma longa série de conflitos armados acontecidos já no presente século e que tivemos oportunidade de expor em Mapas anteriores. (WAISELFISZ, 2016, p. 70)

É preciso considerar que o estudo citado de Waiselfisz (2016) leva em consideração somente os homicídios dolosos causados por arma de fogo, enquanto os dados do IPEA (2018) e do Fórum Brasileiro de Segurança Pública (2018), consideram todas as ocorrências. Isto significa que a situação do Brasil é ainda pior: o número de mortes é superior a todos os conflitos citados pelo autor em questão, se vivendo num estado de violência mais grave e com muito mais vítimas do que inúmeras guerras ao redor do mundo.

Aliás, o historiador britânico Eric Hobsbawn (1995) lembra que na Guerra da Coreia e na Guerra do Vietnã, conflitos da segunda metade do século XX, recordados por sua grande violência, morreram aproximadamente 50 mil soldados norte-americanos em cada um destes eventos. Este número, como aqui salientado, é aproximadamente o mesmo, em relação aos brasileiros que morrem anualmente em virtude da crise na segurança pública nacional. Este dado fica mais assustador, quando se considera que o montante de baixas militares se deu no transcurso de vários anos de conflito acirrado, seja na Coreia ou no Vietnã, enquanto o montante de homicídios brasileiros correspondente é verificado a cada ano.

Dando prosseguimento, será analisada a taxa de homicídios por 100.000 habitantes na próxima figura:

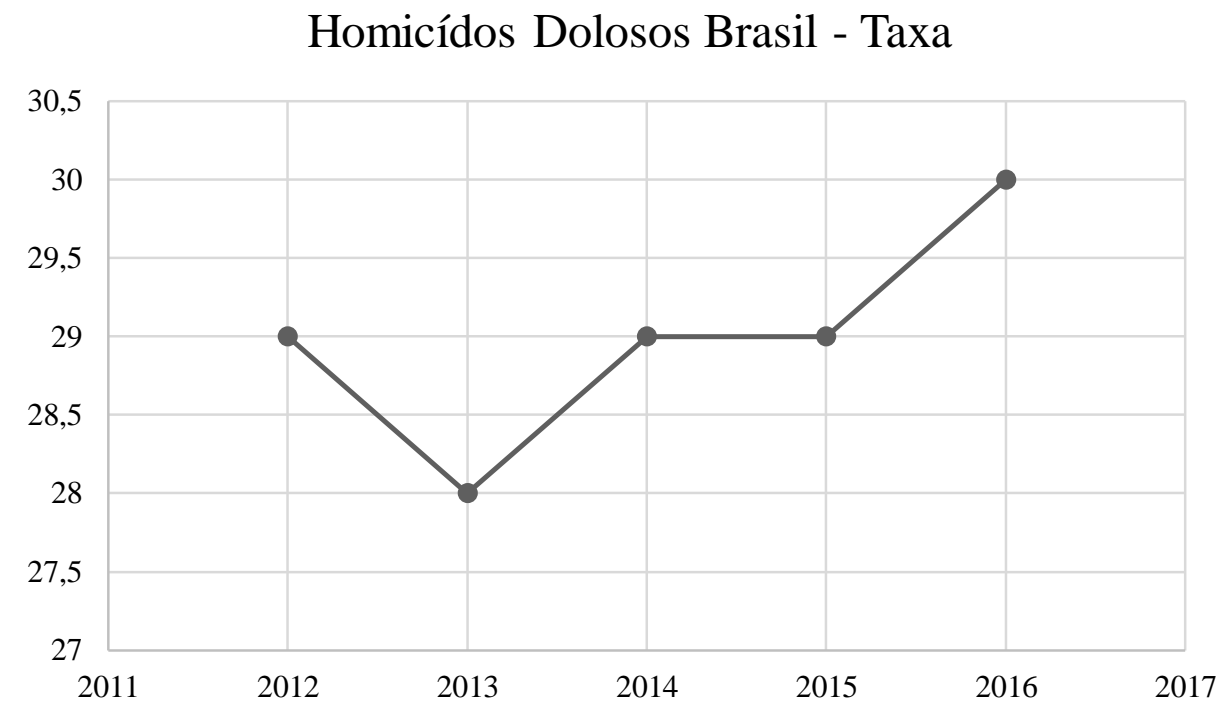


Fig. 02 - Homicídios Dolosos no Brasil - Taxa (2012-2016), Fontes dos Dados: (IPEA, 2018; FORUM BRASILEIRO DE SEGURANÇA PÚBLICA, 2018).

Como visto, ainda que digam respeito ao mesmo fato social, quer seja, homicídios dolosos no Brasil, os números relativos e absolutos não parecem variar da mesma forma. Assim, a taxa de homicídios variou bem menos que os números totais, logo, no período inicial da pesquisa, o Brasil verificou aproximadamente 29 homicídios dolosos a cada 100.000 habitantes no ano de 2012. Este índice caiu para 28 em 2013, voltado para 29 nos dois anos seguintes, 2014 e 2015, respectivamente. Ao término de 2016 houve um ligeiro acréscimo, e o Brasil fechou com a taxa de 30 homicídios a cada 100.000 habitantes (IPEA, 2018; FÓRUM BRASILEIRO DE SEGURANÇA PÚBLICA, 2018).

Embora, como dito, os números relativos não impressionem é preciso considerar que a taxa mundial é de aproximadamente 6,2 homicídios dolosos a cada 100.000 habitantes (UNODC, 2013). Assim, o Brasil possui um índice deste tipo de crime aproximadamente cinco vezes superior à média mundial. Aliás, o relatório do "United Nations Office on Crimes and Drugs" (UNODC, 2013), já destacava a situação do país em comparação com outros:

However, homicide levels in some countries in the Americas, such as Brazil, are now stabilizing, albeit at a high level, while in other regions, countries with historically high homicide rates, such as South Africa, Lesotho, the Russian Federation and countries in Central Asia, are managing to break their own cycle of violence and have recorded decreases in their homicide rates. ${ }^{3}$ (UNODC, 2013, p. 13)

Estas informações vindas de uma agência da Organização das Nações Unidas (ONU), revelam claramente que a questão da criminalidade em torno de assassinatos é um problema específico do Brasil, acima de tudo. Pois, como visto, países também com alta taxa de homicídios em várias regiões do mundo tem conseguido reduzir este indicador, ao passo que o Brasil no máximo consegue estabilizar o índice em um patamar muito alto, se ressalte. Por sinal, a UNODC, registra a tendência atual de homicídios através do globo: "The overall trend in the global homicide rate may be a decreasing one, but it is actually an amalgam of very

\footnotetext{
3 "No entanto, os níveis de homicídios em alguns países das Américas, como o Brasil, estão agora se estabilizando, embora em um nível alto, enquanto em outras regiões, países com taxas de homicídio historicamente elevadas, como África do Sul, Lesoto, Federação Russa e países em Ásia Central, estão conseguindo romper seu próprio ciclo de violência e registraram diminuição nas taxas de homicídios." (tradução livre)
} 
diverse, sometimes even opposing, regional and sub-regional trends." ${ }^{4}$ (UNODC, 2013, p. 32). Neste sentido, áreas com acréscimo ou estabilização do número e taxa de homicídios como no Brasil, fogem da tendência mundial de diminuição dos assassinatos.

O próximo indicador social analisado espelha claramente a principal estratégia do Estado brasileiro contra a criminalidade, ou seja, o enfrentamento desta através da força policial, travando uma espécie de "guerra contra o crime". Desta maneira, serão analisadas as mortes de civis decorrentes de operações policiais, consoante a próxima figura:

\section{Mortes Decorrentes de Intervenções Policiais no Brasil}

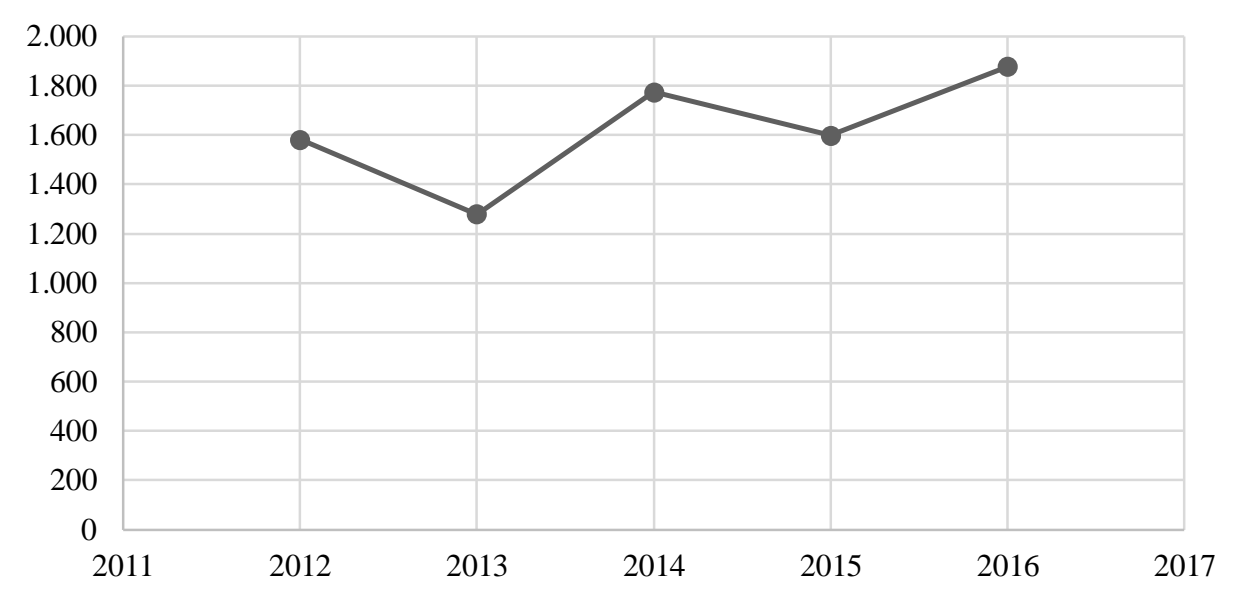

Fig. 03 - Mortes Decorrentes de Intervenções Policiais no Brasil (2012-2016), Fontes dos Dados: (IPEA, 2018; FORUM BRASILEIRO DE SEGURANÇA PÚBLICA, 2018).

A figura 03 mostra que o Brasil possui um elevado números de civis que são mortos em decorrência de ações policiais. A linha traçada no gráfico em questão denota certa estabilidade, mas em patamares numéricos bem altos. Em termos quantitativos, no início do período, quer seja, no ano de 2012, as operações policiais realizadas no Brasil resultaram em 1.581 mortes de civis, criminosos ou não. No ano seguinte, 2013, este número foi reduzido para 1.279. Por sua vez, em 2014, este montante voltou a crescer, alcançando 1.774 casualidades. Contudo, vale a pena lembrar que os dados deste ano não estão completos, pois faltou totalizar a quantidade exata em alguns poucos estados como Amapá e Pernambuco. Nos dois últimos anos do período analisado, 2015 e 2016, foram registrados 1.599 e 1.878

\footnotetext{
4 "A tendência geral na taxa global de homicídios pode ser decrescente, mas é realmente um amalgama de tendências muito diversas, às vezes até opostas, regionais e sub-regionais.” (tradução livre)
} 
mortos em operações policiais, respectivamente, fechando assim, uma tendência de alta da ordem 18,7\% entre o começo (2012) e final (2016) da fase em estudo. Este acréscimo percentual é bem mais elevado que o verificado em relação a homicídios dolosos em geral no país no mesmo período, como discutido anteriormente (IPEA, 2018; FÓRUM BRASILEIRO DE SEGURANÇA PÚBLICA, 2018).

Por fim, o último indicador social analisado será relativo a morte de policiais durante o exercício de funções no Brasil, conforme a figura 04, a seguir exposta:

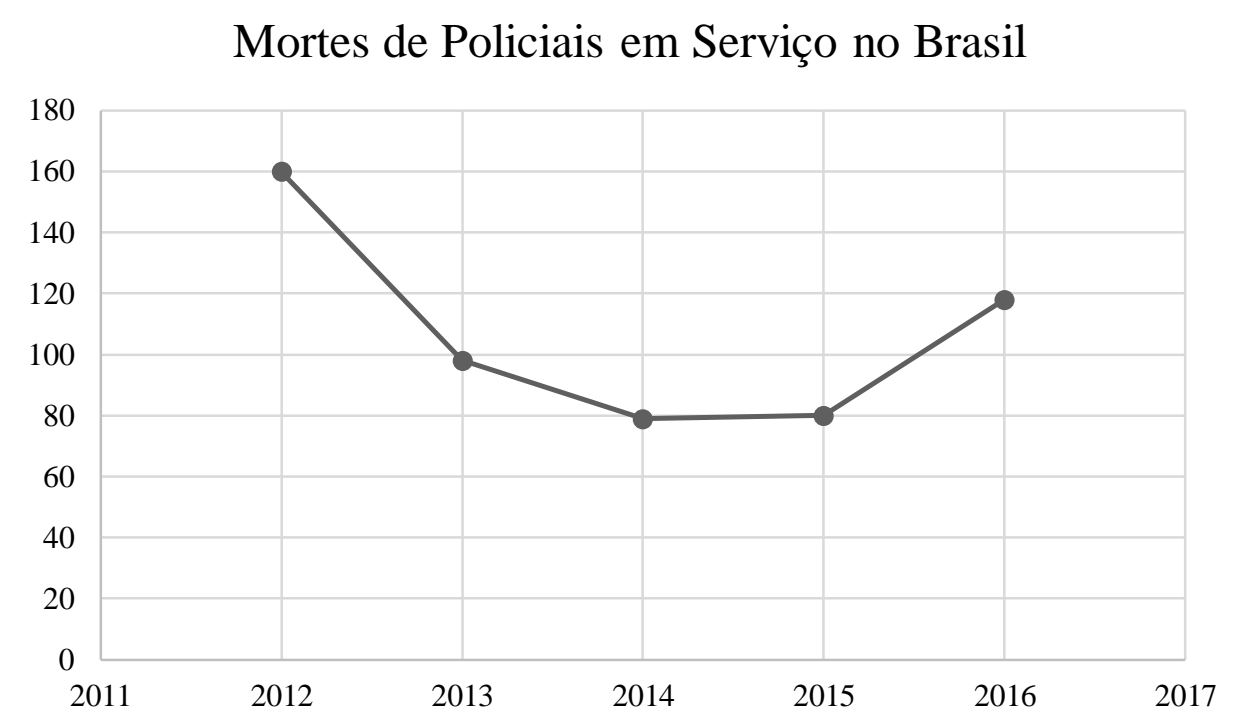

Fig. 04 - Mortes de Policiais em Serviço no Brasil (IPEA, 2018; FORUM BRASILEIRO DE SEGURANÇA PÚBLICA, 2018).

Em primeiro lugar, uma rápida análise visual da figura em questão, mostra que a morte de policiais em serviço no Brasil, é o único indicador social entre os discutidos nesta pesquisa, que se encontra em tendência de queda entre o início e começo do período analisado. Nestes termos, em 2012 foram verificadas 160 mortes de policiais em operações oficiais no Brasil, este número foi reduzido para 98 em 2013, sofrendo novo decréscimo no ano de 2014, quando alcançou 79 mortes. Em 2015 os dados permaneceram relativamente estáveis, se registrando 80 mortes de policiais em serviço, contudo, em 2016 houve uma alta considerável e o montante de profissionais da polícia vitimados chegou a 118. Entretanto, entre o período inicial (2012) e final da pesquisa (2016) se verificou uma considerável redução da ordem de 26,2\% no montante de policiais mortos em serviço no Brasil (IPEA, 2018; FÓRUM BRASILEIRO DE SEGURANÇA PÚBLICA, 2018). 
Os dados apresentados anteriormente, mostraram claramente o número absurdo de homicídios dolosos que ocorreram no Brasil a cada ano. Como salientado pela UNODC (2013), os números de incidência deste crime no país estão instáveis, mas em níveis muito elevados. Segundo já abordado nesta pesquisa, o montante de assassinatos ocorrido no Brasil durante um ano pode ser superior ao número de baixas militares de guerras violentas, não em apenas um, mas em vários anos. Por outro lado, se verifica simultaneamente no Brasil, uma polícia que adota uma postura de guerra contra o crime, que ao mesmo tempo faz muitas vítimas civis em suas operações, mas igualmente fica sujeita a violência, sofrendo um elevado número de baixas fatais dentro das diferentes corporações policiais a cada ano.

Antes de tudo, este trabalho adota uma perspectiva de que o modelo de Segurança Pública no Brasil é ineficiente e está esgotado. Tal modelo foi construído a partir da ditadura militar e se mantem pelas ineficiências do processo transicional brasileiro, como será discutido no próximo e final tópico.

\section{Justiça de Transição, Reformas Institucionais e Segurança Pública no Brasil: consequências de um passado mal resolvido}

Como já dito, este artigo defende a hipótese de que, entre outros fatores, os problemas de Segurança Pública no Brasil são ocasionados pela ausência de reformas institucionais nesta área no contexto do processo de Justiça de Transição no Brasil. Sobre a manutenção do regime de funcionamento do Judiciário e das Forças Armadas após a redemocratização do país, explica o brasilianista norte-americano Anthony Pereira (2010, p. 243):

No entanto, no nível do governo federal, a justiça transicional brasileira foi principalmente simbólica, e o Judiciário e as forças armadas, sob a democracia continuaram a funcionar basicamente da mesma maneira como funcionavam sob o regime militar.

O pesquisador brasileiro Caio Nogueira de Castro (2016), esclarece que a transição política no Brasil se deu pelas próprias necessidades do governo, e, não houve uma ruptura institucional ou conversão abrupta para a democracia. Desta forma, explica o autor: "Esse projeto de transição política negociada objetivava garantir a segurança do regime." (CASTRO, 2016, p. 40). 
A despeito disto, evidentemente, a ordem democrática trouxe algumas mudanças relevantes para a Segurança Pública no Brasil, como detalha Castro (2016, pp. 44-45):

[...] sob novas perspectivas de democracia e cidadania se impuseram reformas no contexto da Segurança Pública, ou seja, a Constituição de 1988 inovou ao tratar da temática da Segurança Pública, de forma específica, como um direito social e um dever de todos para preservação da ordem pública e da incolumidade das pessoas, e explicitou os órgãos de polícia no controle social nas questões internas.

Este pesquisador relembra que durante a ditadura, o tema da Segurança Pública era abordado no texto constitucional dentro do título relativo às Forças Armadas, e que era chamada "Segurança Nacional". Após a Constituição Federal de 1988, se passou a usar a terminologia "Segurança Pública", que foi regulada especificamente pelo artigo 144 da Carta Magna democrática (CASTRO, 2016).

Todavia, há quem veja que a mudança da terminologia "Segurança Nacional" para “Segurança Pública" pela Constituição Federal de 1988 trouxe uma mudança de paradigma nesta área, como salientam os pesquisadores brasileiros Sérgio Reis Coelho e Katya Kozicki (2013, p. 432):

Essa mudança de paradigma importou em uma nova redistribuição das forças de
segurança o país. No modelo de segurança nacional, adotado no período de 1964-
1985 e sob supervisão dos EUA, as Forças Armadas tinham um papel proeminente,
conduzindo ações voltadas par a defesa do Estado e da ordem política e social, bem
como exercendo o papel de coordenação entre as ações das políticas e das próprias
Forças Armadas.

Conforme ressaltam Coelho e Kozicki (2013), é preciso considerar que o modelo de Segurança Nacional adotado pela ditadura militar se inseria no contexto da Guerra Fria de enfrentamento de um inimigo externo, não da lógica de combate à criminalidade interna do país.

Voltando um pouco, em relação às reformas institucionais no setor de Segurança após a redemocratização, Paulo Abrão e o político e pesquisador Tarso Genro (2012) enumeram inúmeras mudanças fundamentais ocorridas: a extinção do Serviço Nacional de Informação (SNI), que foi substituído pela Agência Brasileira de Inteligência (ABIN), criação do Ministério da Defesa, reunindo o comando das Forças Armadas e o subordinando ao poder civil, criação de um novo modelo de Ministério Público, com missão constitucional de proteger a democracia, a ordem jurídica e os interesses sociais e individuais indisponíveis. Também houve a criação da Defensoria Pública da União e da Secretaria Especial de Direitos Humanos, além da extinção de órgãos repressivos como o Destacamento de Operações de 
Informações - Centro de Operações de Defesa Interna (DOI-CODI) e Departamento de Ordem Política e Social (DOPS) e das Divisões de Segurança Institucional (DSI’s), entre outras medidas.

Por outro lado, apesar destas reformas, os autores em questão afirmam que: "De todo modo, ainda são pendentes, por exemplo, uma ampla reforma das Forças Armadas e dos sistemas de segurança pública e de polícia.” (ABRÃO; GENRO, 2012, p. 43). Neste sentido, é possível concluir que as reformas alcançadas foram insuficientes para mudar profundamente o sistema de Segurança Pública brasileira e, talvez até mesmo o modelo adotado com a Constituição Federal de 1988 não seja o mais adequado, como afirmam os pesquisadores a seguir:

Se a reforma no modelo de segurança adotada pela Constituição foi profunda, o que permitiu estabelecer um novo paradigma para as políticas de segurança ("segurança pública"), a experiência recente da América Latina vem propondo uma nova concepção, a denominada "segurança cidadã". (COELHO, KOZICKI, 2013, p. 432)

Caio Nogueira de Castro (2016) esclarece que a Segurança Pública foi abordada no Título V da Constituição Federal de 1988, exatamente na mesma parte que trata da Defesa do Estado e Instituições Públicas, estando ombreada com temas como Estado de Defesa, Estado de Sítio e Forças Armadas. Na verdade, a par das mudanças trazidas pela Constituição democrática, existem também muitas semelhanças com o regime constitucional autoritário anterior, como explica este autor:

Observa-se assim, as semelhanças constitucionais do antigo e novo regime no que
diz respeito à Segurança Pública, ou mesmo a possível continuidade do regime
autoritário no contexto da Segurança Pública após o processo de (re)democratização
com a Constituição de 1988 , justamente pela especificidade da transição política
negociada produzida pelos atores políticos à época com a finalidade da manutenção
do modelo institucional de Segurança Pública militarizado, antidemocrático,
repressivo e limitador das liberdades e garantidas individuais para segurança do
regime. (CASTRO, 2016, p. 47 )

Na visão de Castro (2016), o Estado autoritário ainda está presente no contexto da Segurança Pública no Brasil, através do uso da lógica militar nas policiais militares e Forças Armadas, este autor inclusive destaca que: “[...] em democracias plenas, os militares têm pouca ou nenhuma relevância em assuntos estritamente políticos ou de políticas públicas." (CASTRO, 2016, p. 51).

Isto significa, que mesmo superando o modelo de "Segurança Nacional" da Guerra Fria, o sistema de "Segurança Pública" adotado no Brasil é militarizado e antidemocrático, 
passando longe do ideal de "Segurança Cidadã", mais democrático e aberto, como lembram Sérgio Coelho e Katya Kozicki (2013). Esse sistema é responsável por uma atuação policial violenta que gera vítimas tanto do lado da sociedade civil quanto da própria polícia e não consegue reduzir a criminalidade no Brasil. Esta realidade é exemplificada pela relativa estabilização em altos patamares da taxa de homicídios no país e, ao mesmo tempo, no grande número de mortos através deste tipo de crime, como discutido no tópico anterior, sem esquecer das mortes de civis e agentes em operações policiais.

Diante do exposto, Castro (2016) afirma que o modelo adotado pela Constituição de 1988 foi refratário a mudanças no modo de atuação das forças de segurança, não incorporando valores da Justiça de Transição:

O modelo de Instituição de Segurança Pública adotado pela CF/88 não sofreu influências das dimensões da Justiça de Transição. A manutenção da estrutura e da lógica de combate e guerra das Forças Armadas continuam latentes no trato com o cidadão para a manutenção da ordem pública. (CASTRO, 2016, p. 50)

Castro (2016) entende que o atual modelo de Segurança Pública não corresponde ao Estado Democrático de Direito, pois mantém claros traços antidemocráticos, como por exemplo, o uso das Forças Armadas em situações especiais no contexto interno, e, principalmente na manutenção da ideologia de militarização das polícias, que permite a incidência reiterada de abusos aos direitos fundamentais, justificado pelo discurso de manutenção da ordem pública. Neste sentido, este pesquisador defende que é: “[...] urgente a reconfiguração da Segurança Pública e de sua lógica condizente com os aspectos de justiça de transição e garantia dos direitos fundamentais.” (CASTRO, 2016, p. 50). Em suma:

[...] é possível observar que, mesmo após o processo de transição a lógica militar do período ditatorial no controle interno ainda é aplicada, portanto, exemplifica-se, a lógica do uso de instrumento não democráticos na atual conjuntura política. (CASTRO, 2016, p. 50)

Assim, a transição política representada principalmente através da Constituição Federal de 1988 permitiu:

[...] a continuidade do modelo militarizado na Segurança Pública, no qual perpetua a lógica de combate e guerra da Política Militar - contingente auxiliar e reserva do Exército - no controle e combate dos cidadãos para manutenção da possível ordem pública e da paz social. (CASTRO, 2016, p. 50) 
Esta lógica de táticas de guerra contra o crime, que parece produzir pouco resultado no Brasil, é usada por exemplo, no contexto interno de segurança, nas ações para pacificação das favelas na cidade do Rio de Janeiro, como ressalta Castro (2016):

A previsão legal do uso das Forças Armadas nas questões internas, inclusive esgotando-se as possibilidades das polícias, descreve todo um aparato institucional no uso corriqueiro das Forças Armadas para controle da "Ordem Pública", por exemplo, na "pacificação" de favelas, como foram usadas tropas no Complexo da Maré e em outras favelas da zona norte do Rio de Janeiro [...]. (CASTRO, 2016, p. 51)

Segundo este autor, o uso direto das Forças Armadas no âmbito da Segurança Pública acontece: “[...] sem justificativa plausível para tal ação, já que essa medida não se respalda no entendimento da doutrina internacional de "conflito armado"”. (CASTRO, 2016, p. 50). Para Castro (2016), o ethos do combate e da guerra, da afirmação do poder bélico não é suficiente para resgatar o sentimento da cidadania e garantir uma ordem democrática.

Porém, considerando a intervenção federal decretada na Segurança Pública do estado do Rio de Janeiro em fevereiro de 2018 (COELHO; RAMOS; CRUZ, 2018), se vê que a lógica do militarismo para resolver os problemas de criminalidade se perpetua. A intervenção militar na segurança pública acaba sendo um paliativo, que não resolve os problemas sociais que geram a criminalidade. E, só é possível dentro de um contexto de Justiça de Transição como a brasileira, no qual as reformas institucionais não foram suficientes para a superação da lógica do autoritarismo como forma de resolver os problemas da sociedade. Neste sentido, falta ao Estado brasileiro, a seguinte reflexão trazida pelo pesquisador brasileiro Rodrigo Deodato de Souza Silva (2012, p. 108):

\footnotetext{
Instituições de segurança só podem ter êxito se elas responderem às necessidades de segurança do povo e ganharem a confiança da população, tratando todos os cidadãos de forma justa e reconhecendo suas preocupações em torno do que vem a ser uma segurança eficaz.
}

Nestes termos, o último autor citado defende que a integridade de um sistema de Segurança se refere a adesão ao Estado de Direito na sua prestação. Assim, a construção de uma Segurança Pública de qualidade ultrapassa o mero fortalecimento das agências do setor, como polícias e Forças Armadas, é necessário criar mecanismos e processos de prestação de contas e participação junto à sociedade civil (SILVA, 2012). Como explica Rodrigo Deodato Silva (2012), a democratização da Segurança Pública demanda alguns passos importantes: 
Para atingir esses objetivos, as reformas dos sistemas de segurança e justiça se concentram comumente em quatro principais áreas de reestruturação: construção da integridade do sistema de segurança; estabelecimento de uma responsabilização efetiva; reforço da sua legitimidade e empoderamento dos cidadãos. (SILVA, 2012, p. 107)

Este pesquisador entende que reformar as instituições que promoveram práticas abusivas, no caso as polícias e Forças Armadas brasileira, não transforma só essas instituições, mas: “[...] também os indivíduos que passam de vítimas da opressão para a condição de respeitabilidade de seus direitos pelo próprio Estado.” (SILVA, 2012, p. 107). Aliás, é necessário lembrar que um dos principais elementos da Justiça de Transição é exatamente promover reformas institucionais que permitam a superação de práticas autoritárias:

Para confrontar as atrocidades em massa é preciso —ainda que às vezes esse processo não seja suficiente para punir os perpetradores - estabelecer a verdade sobre as violações e reparar as vítimas. Nesse sentido, é imperioso mudar radicalmente, e em alguns casos dissolver, as instituições responsáveis pelas violações dos direitos humanos. (VAN ZYL, 2011, p. 53)

No caso brasileiro, como destaca Anthony Pereira (2010, p. 244): “[...] o arraigado consenso vigente em meio ao Judiciário e às forças armadas vem evitando reformas nas organizações judiciárias e militares.” E, como salientam Paulo Abrão e Tarso Genro (2012), as reformas institucionais dos sistemas de Segurança e Justiça, visando transformar as Forças Armadas, polícias e Poder Judiciário são imperiosas para criação de uma cultura de respeito à cidadania e integridade social. Desta maneira, é preciso considerar, conforme lembram os autores:

Esse processo de institucionalização de práticas e mecanismos de Justiça de Transição disseminam valores democráticos, o que deve ser uma tarefa que transcenda e conste nas políticas públicas de todos os governos, pois a questão democrática exige olhares permanentemente atentos para qualquer sinal de retrocesso. (ABRÃO, GENRO, 2012, p. 46)

Paul van Zyl (2011), informa que em seu país, a África do Sul, as reformas do setor de Segurança foram imensamente fortalecidas a partir das revelações do relatório da Comissão da Verdade e Reconciliação, e, pela remoção de muitos funcionários importantes que cometeram crimes durante o período do apartheid. Nas palavras deste pesquisador:

A saída desses indivíduos foi decisiva para a transformação do ethos nessas instituições e a restauração da confiança nelas. O processo de transformação do setor de segurança, que passou de fonte opressora e de conflito a uma série de instituições de proteção aos indivíduos e defesa de seus direitos, recebeu um ímpeto adicional 
com o estabelecimento de instituições da justiça transicional após o Apartheid. (VAN ZYL, 2011, p. 60, grifo original)

No caso do Brasil, o relatório da Comissão Nacional da Verdade (CNV) fez importantes recomendações para reformas institucionais dos setores de Segurança. Inclusive, foi sugerido que tanto nos concursos públicos de admissão das Forças Armadas e polícias, quanto no conteúdo curricular de suas academias de formação profissional, se adotassem preceitos inerentes à democracia e respeito aos Direitos Humanos (BRASIL, 2014).

Outras medidas sugeridas foram a desmilitarização das polícias estaduais, a criação de mecanismos de prevenção e combate à tortura, notadamente em instalações policiais, a revogação da Lei de Segurança Nacional (Lei Federal n 7.170/1983), a extinção da Justiça Militar estadual, a exclusão de civis da jurisdição da Justiça Militar federal, a introdução das audiências de custódia para prevenir tortura e prisão ilegal, e, por fim a eliminação dos autos de resistência à prisão. Esta última figura jurídica é usada para justificar legalmente mortes de civis decorrentes de operações policiais (BRASIL, 2014).

Salvo a questão das audiências de custódia, é possível ver que as recomendações de reformas institucionais da $\mathrm{CNV}$ não encontraram respaldo tanto no Estado, quanto na sociedade brasileira em geral. Esta pesquisa, acredita que este fato se deve, em vista de que o relatório da Comissão da Verdade foi divulgado quase três décadas após o fím do regime ditatorial, ou seja, quando a ditadura militar já era um fato histórico distante das gerações mais jovens. Vale a pena lembrar que na África do Sul e em outros países como a Argentina e Chile, este tipo de entidade foi criada imediatamente após o término do regime autocrático (TEITEL, 2011; PEREIRA, 2010, VAN ZYL, 2011).

Assim, a lentidão, a falta de capilaridade e de respaldo social do processo de Justiça de Transição no Brasil contribuíram para o cenário de continuação da ideologia e lógica do militarismo na área de Segurança no país. Uma estratégia claramente ineficiente para lidar com a criminalidade, pois permite a continuação do Brasil entre os líderes em homicídios dolosos ao redor do mundo.

\section{Considerações Finais}


O modelo de Segurança Pública adotado pelo Brasil após a Constituição Federal de 1988, além de ineficiente, pode ser entendido como um modelo esgotado e superado. Afinal, com visto no segundo tópico deste trabalho, o país tem um número de homicídios dolosos a cada ano, equivalente ao de guerras violentas como Vietnã e Coreia. A estratégia militarista de enfretamento contra o crime através de mecanismos de guerra, produz um elevado número de pessoas assassinadas, sejam civis ou policiais mortos.

Ao que parece, a sociedade brasileira em geral e o Estado ainda não se deram conta da falência deste modelo. A melhor prova disso é a insistência na estratégia de intervenção militar para a crise de Segurança que o Brasil vem enfrentando.

Na verdade, este trabalho defende a perspectiva de que, este modelo de Segurança se perpetuou no país graças a um processo de Justiça de Transição ineficiente, que não conseguiu esquecer as práticas do autoritarismo e, especialmente, superar o militarismo como forma de resolver problemas sociais, no caso a criminalidade, dentro da perspectiva estrita do Estado Democrático de Direito. Logo, o que o Brasil necessita é a construção de um sistema de "Segurança Cidadã", elaborado democraticamente, com a participação de toda a sociedade e voltado para o controle da criminalidade, dentro dos marcos da legalidade e do respeito aos Direitos Humanos. Também falta um processo de Justiça de Transição mais efetivo, que imprima na sociedade a ideia de que possível criar uma nação com justiça, ordem e segurança sem apelar ao militarismo e autoritarismo.

Falta ainda, sobretudo, sedimentar na sociedade brasileira, a ideia de que a democracia não se esgota em eleições. Ela deve ser uma prática social constante que permeie outros todos os setores da vida social, a exemplo da Segurança.

\section{REFERÊNCIAS}

ABRÃO, Paulo. Direito à Verdade e à Justiça na Transição Política Brasileira. In: ; GENRO, Tarso. Os Direitos da Transição e a Democracia no Brasil: estudos sobre justiça de transição e teoria da democracia. Belo Horizonte: Fórum, 2012, pp. 59-80.

; __ Os Direitos da Transição no Brasil. In: ABRÃO, Paulo; GENRO, Tarso. Os Direitos da Transição e a Democracia no Brasil: estudos sobre justiça de transição e teoria da democracia. Belo Horizonte: Fórum, 2012, pp. 33-47. 
BICKFORD, Louis. Transitional Justice. In: The Encyclopedia of Genocide and Crimes Against Humanity. USA: Macmillan Reference USA, 2004, vol. 3, pp. 1045-1047.

BRASIL. Comissão Nacional da Verdade (CNV). Relatório da Comissão Nacional da Verdade. Brasília: CNV, 2014, v. 1. Disponível em:

$<$ http://www.cnv.gov.br/index.php/outrosdestaques/574-conheca-e-acesse-o-relatorio-finalda-cnv>. Acesso em: 15 jan. 2015.

CASTRO, Caio Nogueira de. A Segurança Pública no Processo de (Re)democratização no Brasil à luz da Justiça de Transição. In: BELLO, Enzo; FRISSO, Giovanna Maria;

MARTINELLI, João Paulo Orsini (orgs.). Direitos Humanos e Justiça de Transição. São Paulo: LiberArs, 2016, pp. 39-55.

COELHO, L.; RAMOS, M. V.; CRUZ, M. T. Intervenção federal no Rio, a nova cara das ações militares que fracassam há décadas. El País. 18 fev. 2018. Disponível em:

<https://brasil.elpais.com/brasil/2018/02/17/politica/1518877928_723230.html>. Acesso em 18 fev. 2018.

COELHO, Sérgio Reis; KOZICKI, Katya. As Dimensões e Limites da Justiça de Transição no Brasil: a decisão do STF e da jurisprudência da Corte Interamericana de Direitos Humanos no Fortalecimento das Instituições Democráticas. In: SILVA FILHO, José Carlos Moreira da; ABRÃO, Paulo; TORELLY, Marcelo (coord.). Justiça de Transição nas Américas: olhares interdisciplinares, fundamentos e padrões de efetivação. Belo Horizonte: Fórum, 2013b, pp. 423-439.

INSTITUTO DE PESQUISA ECONÔMICA APLICADA (IPEA). Atlas da Violência. Disponível em: <http://www.ipea.gov.br/atlasviolencia/series>. Acesso em 12 fev. 2018.

FORUM BRASILEIRO DE SEGURANÇA PÚBLICA. Dados em Tabelas. Disponível em: $<$ http://www.forumseguranca.org.br/estatisticas/tableau-ocorrencias/>. Acesso em 13 fev. 2018.

HOBSBAWN, Eric J. Era dos Extremos: o breve século XX: 1914-1991. 2. Ed. São Paulo: Companhia das Letras, 1995.

PEREIRA, Anthony W. Ditadura e Repressão: o autoritarismo e o estado de direito no Brasil, no Chile e na Argentina. São Paulo: Paz e Terra, 2010.

QUINALHA, Renan Honório. Justiça de Transição: contornos do conceito. São Paulo: Outras Expressões; Dobra, 2013.

SILVA, Rodrigo Deodato de Souza. Para Além da Mera Reforma: reflexões sobre as relações entre Justiça de Transição, Direito Penal e Política Criminal. In: SILVA FILHO, José Carlos Moreira da (org.). Justiça de transição no Brasil: violência, justiça e segurança. Porto Alegre: EDIPUCRS, 2012, pp. 97-111. Disponível em: < http://www.pucrs.br/edipucrs>. Acesso em: 22 out. 2016. 
TEITEL, Ruti G. Genealogia da Justiça Transicional. In: REÁTEGUI, Félix (org.). Justiça de Transição: manual para a América Latina. Nova York: Centro Internacional para Justiça de Transição, 2011, pp. 135-170.

Global Transitional Justice. New York: New York Law School, 2010. Disponível em: <https://www.gmu.edu/centers/globalstudies/publications/hjd/hjd_wp_8.pdf>. Acesso em 11 jan. 2017.

\section{UNITED NATIONS OFFICE ON DRUGS AND CRIME (UNODC). Global Study on}

Homicide (2013). Disponível em:

<https://www.unodc.org/documents/gsh/pdfs/2014_GLOBAL_HOMICIDE_BOOK_web.pdf $>$. Acesso em 28 jul. 2017.

VAN ZYL, Paul. Promovendo a Justiça Transicional em Sociedades Pós-conflito. In:

REÁTEGUI, Félix (org.). Justiça de Transição: manual para a América Latina. Nova York:

Centro Internacional para Justiça de Transição, 2011, pp. 47-71.

WAISELFISZ, Julio Jacobo. Mapa da Violência 2016: homicídios por arma de fogo no Brasil. Disponível em:

<http://www.mapadaviolencia.org.br/pdf2016/Mapa2016_armas_web.pdf >. Acesso em 16 fev. 2018. 